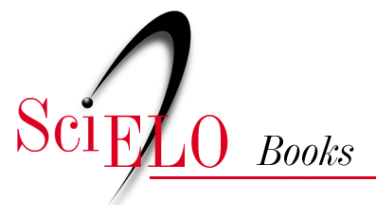

\title{
10 - Aproximações entre sociologia rural e o campo da arte: transformações simbólicas no sertão cearense
}

\author{
Nicole Sousa Bessa \\ Kadma Marques Rodrigues
}

\section{SciELO Books / SciELO Livros / SciELO Libros}

BESSA, N. S., and RODRIGUES, K. M. Aproximações entre sociologia rural e o campo da arte: transformações simbólicas no sertão cearense. In: OLIVEIRA, G. M. C., and VIEIRA, K. M. A., eds. Patrimônio, povos do campo e memórias: diálogos com a cultura, a arte e a educação [online]. Mossoró: EdUFERSA, 2020, pp. 153-163. ISBN: 978-65-87108-09-4.

https://doi.org/10.7476/9786587108605.0011.

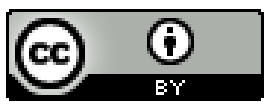

All the contents of this work, except where otherwise noted, is licensed under a Creative Commons Attribution 4.0 International license.

Todo o conteúdo deste trabalho, exceto quando houver ressalva, é publicado sob a licença Creative Commons Atribição 4.0.

Todo el contenido de esta obra, excepto donde se indique lo contrario, está bajo licencia de la licencia Creative Commons Reconocimento 4.0. 


\title{
10 APROXIMAÇÕES ENTRE SOCIOLOGIA RURAL E O CAMPO DA ARTE: TRANSFORMAÇÕES SIMBÓLICAS NO SERTÃO CEARENSE
}

\author{
Nicole Sousa Bessa \\ Kadma Marques Rodrigues
}

\section{Introdução}

A sociologia com ênfase na identificação das práticas sociais no mundo rural assume novos contornos ao abordar elaborações simbólicas que partem de contextos específicos e que têm relação direta com a produção material da vida em sociedade. Nesse contexto, a sociologia desempenha um papel importante na compreensão do modo como formas simbólicas, a exemplo daquelas produzidas pela arte, dialogam com o vivido, com o cotidiano, mediando interações sociais diretas. Assim, igualmente norteada pela perspectiva da sociologia da arte, a presente pesquisa teve como objetivo, analisar as transformações sociais provocadas pela expansão da arte urbana nas cidades do sertão cearense, mais especificamente aquelas propiciadas pelo projeto $\mathrm{RASTRO}^{39}$, pelos elementos que o integram a partir dos efei-

39 O projeto foi contemplado em edital de Incentivo as Artes pela Secretária de Cultura do Estado do Ceará e pela Caixa Cultural de Fortaleza, que forneceu apoio e possibilidade de realização da exposição dos trabalhos feitos pelo artista no sertão cearense no complexo "Caixa Cultural" na cidade de Fortaleza. A ideia do projeto era o artista fazer intervenções de arte em casas que conservassem características do sertão a partir de histórias contadas pelos moradores das cidades. 
tos pretendidos pelo artista no deslocamento da arte pública urbana ao universo rural.

No momento, é este o aspecto que confere maior relevância a esta pesquisa: o fato de que estudos acadêmicos recentes, tão atentos a interconexões entre o mundo rural e o urbano, tenham se dedicado pouco a compreender os efeitos da expansão dessa arte em uma zona diversa daquela que a originou. De fato, quando o desenvolvimento dessa categoria de arte se volta para o campo, estabelece novas conexões com o social, provocando transformações simbólicas desses espaços.

\section{A Sociologia Rural como chave de interpretação das novas ruralidades no contexto do Nordeste}

Para compreender como se caracterizava a sociologia rural em seu surgimento, é importante recorrer a fontes teóricas e historiográficas que apontam contribuições significativas para a análise das transformações do emprego do termo "rural", tanto no Brasil, quanto no Nordeste.

Durante muitos anos o rural era concebido pelos sociólogos como o lugar da escassez, da falta e do atraso. Tais análises se baseavam muito mais na imagem inventada sobre como era o rural e seus habitantes, do que no modo concreto de ser e fazer das populações rurais (CARNEIRO, 2008, p. 10).

Ao contrário dessa perspectiva, neste trabalho, estabeleceu-se um contato itinerante e de proximidade com o cotidiano das populações rurais no Ceará. Ao longo de meses de pesquisa de campo, observamos que as relações que se constroem nestas cidades são de aconchego, fartura e conhecimento cultural. Apesar de predominar ainda a seca e a maior parte da população trabalhar em atividades agrícolas, as pessoas demostram outro olhar sobre o sertão, diverso daquele da falta e do atraso.

Segundo Giordano (1989 apud CARNEIRO, 2008, p. 10), podemos reconhecer a "grosso modo" na sociologia de tradição urbana e industrial, uma valorização da cidade como um espaço do progresso, da modernidade e da civilização, e o rural como o lugar do atraso, "da tradição e do estático". Portanto, segundo diversos autores, a sociologia rural foi elaborada como uma disciplina "instrumental e tecnocrática voltada para o desenvolvimento, a eficácia e a modernização da produção agrícola”. 
Deste modo, tudo indicava que os modelos industriais e urbanos deveriam se sobrepor de forma definitiva como modo de estruturação da vida no campo, "transformando a agricultura em 'um ramo a mais da indústria' e os agricultores em produtores e habitantes suburbanos" (GIULIANI, 1990, p. 1). Segundo o autor, a cidade tinha tudo para oferecer ao campo e este nada tinha que pudesse servir à cidade. Os seus modelos produtivos e socioculturais podiam permanecer interessantes para alguns poucos "cultores da história e do folclore, mas nem aos próprios agricultores interessavam mais" (GIULIANI, 1990, p. 1).

Do mesmo modo, Williams (2011) afirma que no campo se mantém uma "forma natural de vida, de paz, de inocência", ao passo em que a cidade é onde se constroem as grandes realizações humanas. Porém, os aglomerados urbanos teriam seu lado negativo, de "barulho, ambição", perpetuando um contraste entre campo e cidade que se anunciou desde a Antiguidade clássica.

O rural também foi abordado por antropólogos que estudavam as sociedades camponesas, "primitivas" e exóticas. O campo era então percebido cientificamente como o lugar protegido da violência, da criminalidade e do desvio, pois era afastado inclusive espacialmente dos males que advém da cidade que, ao longo do tempo, passa a ser representada como uma ameaça ao meio rural (CARNEIRO, 2008, p. 23).

Porém, a problematização desta linha de análise demonstrou, por observações e relatos coletados em campo, que a população não se sentia mais segura nas cidades do interior, pois os problemas sociais aconteciam de modo semelhante, tanto nas cidades localizadas em meio urbano, como rural.

Atualmente, a sociedade brasileira passa a lançar um novo olhar sobre o meio rural, em oposição àquela perspectiva que o designava como lugar do atraso, fonte de problemas, miséria, currais eleitorais. Segundo Wanderley (2001), surgem indícios de que "o meio rural pode ser percebido igualmente como portador de 'soluções', um lugar positivo para alternativas como o emprego, melhoria da qualidade de vida, por meio do turismo rural ou residências rurais que propiciem o contato mais direto com a natureza e o aprofundamento das relações sociais no campo" (WANDERLEY, 2001, p. 31). 
Na região Nordeste, o turismo rural passa a constituir uma importante fonte de renda para as pequenas comunidades, ampliando o investimento de diversas esferas das políticas públicas nessa região. O problema é que nas mídias de grande circulação, o Nordeste permanece sendo o lugar da seca e da ignorância, aproveitando-se apenas a vertente do turismo natural com base nas belas praias de dunas claras e areia fina.

Por sua vez, a análise de Albuquerque Jr. (2011), aponta a importância da integração simbólica do Norte-Nordeste com o espaço nacional, pois as análises sociológicas e antropológicas formuladas por certos autores atribuem uma identidade cultural à região Nordeste que acaba por reproduzir as fissuras e hierarquias sociais constituídas em relação a este espaço. $\mathrm{O}$ autor afirma que "nos trabalhos dos intelectuais que adotam os paradigmas naturalistas, seja pelo próprio discurso da seca, o Norte aparece como uma área inferior do país pelas próprias condições naturais [...]" (ALBUQUERQUE JR., 2011, p. 69). Assim, durante muitos anos, o Nordeste e os nordestinos foram, por meio de discursos, caracterizados como um problema a ser resolvido, e por meio de imagens, que naturalizavam a perspectiva de "estereotipização".

No que concerne ao Nordeste, temos o sertão caracterizado por artistas e intelectuais brasileiros, na década de 1950 e 1960, como o espaço do autêntico, da cultura e da identidade nacional, mas essa classificação sofreu mudanças e ressignificações, ganhando um valor simbólico para a cultura popular nordestina (ALVES, 2009, p. 10).

Segundo o autor, criou-se uma narrativa simbólica do significado de sertão nordestino, com a "expansão dos mercados culturais urbanos e a consolidação do valor de exposição", os artistas e intelectuais, a partir de uma postura crítica com vários desdobramentos, acabaram criando uma “espécie de estatuto social da 'pureza' e da 'autenticidade”, atribuindo ao sertão nordestino uma memória social ligada ao interior da região, que está "diretamente ligada aos principais centros urbanos do país" (ALVES, 2009, p. 12/20).

Diante disso, podemos perceber que essa significação do sertão existe e é concebida como a memória do lugar da seca, atribuída pelos autores que disseminam culturalmente as histórias dos nordestinos, sempre interiorizando 
a região Nordeste que emerge como o lugar da seca, do retirante, da fome, da "violência mítica e heroica do cangaço", marcado pela crença em um líder religioso local, como padroeiros das cidades (ALVES, 2009).

Temos o exemplo da crença no padroeiro São José, muito importante na cultura do nordestino e no Ceará. Reza a lenda que se não chover no dia do santo, o ano será de secas e privações. Está imbuído na memória e imaginação do sertanejo que, se chover, o ano será de abundância nas colheitas e o povo não passará fome e nem sede.

Porém, segundo Alves (2009), atualmente a chuva não é mais tão decisiva em relação a alimentação e felicidade do povo, mesmo que ainda ocorra o fenômeno da seca. Nos anos 1990, foram criadas ações governamentais para impulsionar a economia dos médios e pequenos municípios do Nordeste, região com um grande contingente populacional, em sua maioria, relacionado às outras regiões do país. Foram criadas cidades sedes com infraestrutura básica, de serviços, de educação, saúde, prefeituras, incentivando a formação de recursos profissionais e impulsionando a economia dos estados.

Podemos perceber durante o percurso da pesquisa que as cidades do percurso apresentam uma estrutura básica de serviços públicos, estruturadas geralmente por uma cidade sede para atender às necessidades da população rural, que estão nos arredores do município.

Mesmo com o desenvolvimento econômico dessas cidades, ainda permanecem ecos do significado de um sertão imaginado, elaborado há muito tempo por diversos agentes e instituições. Um número considerável de publicações no final do século XX, difundidas em jornais e revistas pelo país, propagava uma imagem sofrida da região. Tal imagem, urdida muitas vezes pelo compartilhamento de fotografias da seca, era interpretada pelos intelectuais como a "tragédia sertaneja", reforçada por uma narrativa dos cenários e das canções que cristalizam o significado de sertão perante o centro-sul do país (ALVES, 2009).

Se a fotografia documental subsidiou fartamente este imaginário, os artistas contemporâneos constituem mais recentemente, por meio de intervenções e imagens, uma representação do Nordeste e da identidade nordestina que articula diferentemente aspectos sociais, corporais, culturais, políticos e econômicos. Inversamente à tendência seguida por 
intelectuais naturalistas, o Projeto RASTRO corresponde a um segmento do setor cultural que busca reafirmar e valorizar a cultura sertaneja local, tal como seus habitantes a concebem.

Podemos identificar na entrevista com uma das moradoras de Ocara, o reconhecimento da cultura que os mesmos elaboram em diálogo com meios de comunicação de massa, a exemplo da televisão, redes sociais e rádios. Segundo a moradora as intervenções artísticas em sua casa e na cidade representam:

(Algo) muito rico. Achei uma ideia brilhante, porque eu adoro todas essas coisas aí. Tô até pensando em colocar no meu quarto. Eu acho muito importante, tudo que é arte [...] agora a gente nem pode derrubar, porque já faz parte da cultura, se tornou um cartão postal. Por causa dessa pintura o Lázaro ${ }^{40}$ se tornou um moldador de quadros, recebeu um convite e emoldurou. Pra você ver como a arte inspira novamente [...] Eu achei essa pintura muito dinâmica, muito suspirada. O Weaver era uma boa pessoa e também tinha o Edjonh ${ }^{41}$ que contribuiu... Eu acho assim macho, pra mim a arte do improviso é uma riqueza, a pintura pra mim é uma expressão viva, moldada num sentimento de alegria, é uma maneira de você mostrar o sentimento através de cores e formas. ${ }^{42}$

Segundo Carneiro (2008), essas novas experiências criativas "se nutrem de uma diversidade social e cultural que, por sua vez, alimenta as trocas, enriquecendo os bens (culturais e simbólicos) e ampliando a rede de relações sociais" das populações que habitam o interior do Estado.

A permanência e importância do rural, como espaço integrado, no entanto peculiar e distinto, é reforçada quando são consideradas as representações sociais geradas in loco como fonte de conhecimento do próprio meio rural. Segundo Wanderley (2001), é que mesmo quando se percebe

40 Seu Lázaro (marido de dona Ueudes Batista). Ambos foram entrevistados.

41 Artista local da cidade de Ocara que contribuiu em conjunto com o Weaver nas intervenções artísticas na cidade.

42 Entrevista concedida em maio de 2017. 
certa homogeneidade, "no que se refere aos modos de vida e à chamada 'paridade social', as representações sociais dos espaços rurais e urbanos reiteram diferenças significativas, que têm repercussão direta sobre as identidades sociais, os direitos e as posições sociais de indivíduos e grupos, tanto no campo quanto na cidade" (WANDERLEY, 2001, p. 33).

Essas diferenças não se encontram apenas no nível de acesso a bens de consumo ou materiais entre campo e cidade, mas sim nas "identificações e reivindicações na vida cotidiana, de forma que o 'rural' se torna um 'ator coletivo', constituído a partir de uma referência espacial e 'inserido num campo ampliado de trocas sociais' (WANDERLEY, 2001, p. 33)”.

Podemos compreender a partir desta análise que não há limites rígidos que oponham o universo simbólico do campo àquele da cidade. Muito da origem de hábitos mantidos por gerações passadas (avós, pais, tios) pertence ao interior. Mas também ela se conforma ao longo do tempo à realidade das grandes cidades, por meio de intercâmbios que se estabelecem no contato entre populações da cidade e do campo. Do mesmo modo, a arte urbana se realoca no campo, mediante a criação de formas e conteúdos que difundem a cultura local, neste e em outros lugares.

Essa diversidade e dinâmica de produção cultural pode agir no sentido de moldar as identidades de diferentes grupos ao permitir uma consciência de si na relação com o outro, que segundo Carneiro (2008, p. 33), "pode contribuir igualmente para a definição de uma identidade urbana no interior de uma localidade tida como rural e vice-versa".

Para Wanderley (2001, p. 34), se a vida local é decorrência do encontro recorrente entre o rural e "o urbano e o desenvolvimento local, entendido como o processo de valorização do potencial econômico, social e cultural da sociedade local, não pode supor o fim do rural." Então para a autora, o desenvolvimento local, será muito abrangente quando congregar e der valor ao potencial social existente no meio rural, concorrendo para o próprio desenvolvimento rural. 
Portanto, considerando a existência dessas inúmeras relações sociais nessas localidades, podemos analisar o desenvolvimento do papel dos chamados neo-rurais. Estes fornecem estímulos às relações de sociabilidade e à criação dos laços de solidariedade, com a implementação de projetos coletivos, associações e grupos (CARNEIRO, 2008, p. 33).

Segundo Giuliani (1991), o neoruralismo propaga os valores antigos, típicos do velho mundo rural, os quais passam por um processo de fortalecimento e conseguem atrair a atenção de pessoas da cidade. A relação direta com a natureza, o trabalho mais tranquilo e menos rígido, o ar mais puro e a qualidade de uma vida pautada por relações sociais de vizinhança mais espontâneas atraem as pessoas da cidade para o campo. Segundo o autor, a base do neoruralismo é essa forma das pessoas irem ao campo, que no Brasil tem "dimensões completamente desconhecidas, embora seja possível identificar com facilidade, em todas as diferentes regiões do país, um certo número de 'novos rurais'" (GIULIANI, 1991, p. 2).

Então, para o autor, o local e o regional deixam de ser diferenciados como limites "constrangedores cuja superação é insistentemente incentivada pela ideologia homogeneizadora e modernizante”, pois se tornam perfis de uma identidade que deve ser modelada, definida e realizada (GIULIANI, 1991, p. 5).

Para Carneiro (2008), as inúmeras reflexões sobre o rural, mostram a ruralidade como um processo dinâmico que leva em consideração os elementos da cultura local, ao mesmo tempo em que ocorre a atração de "novos valores, hábitos e técnicas". De um lado, caracteriza-se pela "reapropriação dos elementos da cultura local a partir de uma releitura possibilitada pela emergência de novos códigos" e, de outro, "a apropriação pela cultura urbana de bens culturais e naturais do mundo rural”, que viabilizam e contribuem para fortalecer os laços de sociabilidade com a localidade (CARNEIRO, 2008, p. 33).

Neste sentido, como podemos analisar as intervenções artísticas realizadas pelo Projeto RASTRO em um espaço social portador de capital simbólico específico, para fazer desse "novo mundo rural um lugar de inovação social”? 
A ideia inicial do projeto era deixar um grande desenho em cada cidade. Porém, com o decorrer da ação e a repercussão entre os moradores, Weaver começou a difundir outros desenhos, sem que estes estivessem presos a parâmetros ou quantidades definidos previamente. A realização do projeto também abandonou a delimitação de uma quantidade limitada de cidades (vilarejos) que receberiam a intervenção. Para a primeira exposição, foram 11 cidades percorridas. Cada intervenção era realizada em um dia. Caso chovesse, eram necessários 2 ou 3 dias. Havia também outros imprevistos como a temperatura local que, via de regra, era muito elevada. Por isso, era preciso também levar em conta o clima seco do sertão, a necessidade de local para descansar ou dormir, a duração da estadia para a realização das intervenções. Segundo Weaver,

[...] as pessoas eram receptivas. Traziam café, lanchinho... No interior, você trabalha com pessoas que são "gente" e sempre estão perguntando se você quer alguma coisa. Já pintei em várias cidades e não tem nada como pintar no interior. As pessoas estão rindo, contando histórias, é uma experiência muito rica para compreender as pessoas.

As intervenções/desenhos foram construídas a partir de histórias vivenciadas pelos próprios moradores e narradas ao artista. Weaver levava sempre um caderninho à medida que passava pelas cidades, colhendo notas sobre elementos de textura, tornando-se este material um grande guia de referências nos processos de criação. Assim, ele afirma que: "geralmente quando eu chego na cidade onde vai ser feita a pintura é que eu vou construindo a ideia do que vai ser feito ali. Não vou mais com nada pré-definido".

Tais intervenções afirmam o intuito de valorizar a cultura local como um fator de inclusão social a partir de um projeto que garantiria assim à população do campo o contato com a arte por meio de uma ação aliada à atuação política governamental em suas diferentes esferas, propiciando a todos o acesso à diversificação de bens culturais (WEAVER, 2016).

\section{Considerações finais}

É possível compreender que o Projeto RASTRO elaborou-se na perspectiva de garantir a democratização da arte, dando à população sertaneja o acesso 
ao processo de criação e de fruição das formas de arte. A partir das intervenções criadas, configura-se uma relação diferenciada dos habitantes do sertão do Ceará com suas memórias, suas casas e sua cidade, mediante a exposição de suas histórias nas fachadas de suas moradias.

Quando a arte que tem características urbanas, por ter emergido nesse contexto, propõe-se à expansão é possível perceber a intensificação de seu poder de intervenção no cotidiano. Neste caso, ao tratar histórias simples, vividas no dia-a-dia, o artista cria uma aproximação entre sua produção e um "público" afetado pela conversão de suas histórias em imagens.

A arte urbana, revela-se assim como elemento propulsor de hibridizações entre práticas e significados próprios à vida urbana e aqueles que emergem do sertão, despontando como forma artística que assinala a transição para um momento pós-industrial, ao imprimir sua marca no imaginário coletivo de pequenas e grandes cidades do mundo.

As práticas sociais no mundo rural são identificadas nesta pesquisa por meio das intervenções artísticas nas fachadas das casas pelo artista que se constroem nos momentos de criação das intervenções artísticas, a partir de histórias vivenciadas e narradas pelos próprios moradores ao artista. Desse modo, pode-se afirmar que o Projeto RASTRO não só subsidiou um processo de democratização da arte dita urbana, mas fortaleceu sociabilidades e vínculos comunitários da população sertaneja, por meio do processo de criação e fruição compartilhada das formas de arte fundidas à fachada das casas dos habitantes das cidades por onde passou o projeto. 


\section{REFERÊNCIAS}

ALBUQUERQUE JR, D. M. A Invenção do Nordeste e outras artes. 4. ed. Recife: FJN; Massangana; São Paulo: Cortez, 2009. 340 p. ALVES, E. P. M. A Economia simbólica da cultura popular sertanejo-nordestina. 2009. 385 f. Tese (Doutorado em Sociologia) Universidade de Brasília, Brasília, 2009.

CARNEIRO, M. J. "Rural" como categoria de pensamento. Ruris, v. 2, p. 09-39, 2008.

CARNEIRO, M. J. Ruralidades contemporâneas: modos de viver e pensar o rural na sociedade brasileira. Rio de Janeiro: FAPERJ, 2012. GIULIANI, G. M. Neo-ruralismo: o novo estilo dos velhos modelos. Rev. Bras. Ci. Soc., v. 5, n. 14, out. 1990. Disponível em: https://bit. ly/33lDtUU. Acesso em: 17 fev. 2020.

WANDERLEY, M. N. B. A Ruralidade no Brasil moderno: por um pacto social pelo desenvolvimento rural. In: GIARRACCA, N. (Org.). ¿Una nueva ruralidad en América Latina? Buenos Aires: CLASCO, $2001 \mathrm{~b}$. Disponível em: https://bit.ly/3mp58xg. Acesso em: 10 mar. 2017. WEAVER, F. RASTRO uma expo de Weaver F. Fortaleza: Monstra, 2016. 